\title{
Experimental and analytical investigation on the coupled elastoplastic damage model of coal-rock
}

\author{
Yundong Shou* \\ School of Civil Engineering, Wuban University, China \\ shouyundong@wbu.edu.cn, bttps:/ / orcid.org/0000-0001-7424-4006
}

Jianwei Zhang

School of Civil Engineering, Chongqing University, China

20076188@cqu.edu.cn

Filippo Berto

Norwegian University of Science and Technology, Norway

filippo.berto@ntnu.no

ABSTRACT. In this paper, a novel coupled elastoplastic damage model for coal-rock is proposed to predict the deformation and potential disaster in coal mining. The conditions of small deformation and thermodynamic potential are considered, as well as the coupling of damage evolution process with the plastic deformation and the plastic hardening of coal-rock. Based on the theory of damage mechanics, the formulas of damage evolution, plastic yield and plastic potential of coal-rock are deduced theoretically. In addition, triaxial compression tests of coal-rock under the different confining stresses are conducted to reveal the law of deviatoric stress and strain. Based on the experimental data, the control parameters of the coupled elastoplastic damage model of coal-rock are determined. The theoretical results obtained from the coupled elastoplastic damage model for coal-rock agree well with those from the experiment. The proposed model is reasonable to predict the deformation of coal-rock.

KEYWORDS. Coal-rock; Coupled elastoplastic damage model; Damage mechanics; Triaxial compression tests; The deformation prediction of coalrock.

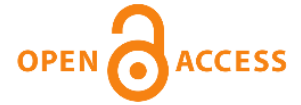

Citation: Shou, Y.D., Zhang, J.W., Berto, F., Experimental and analytical investigation on the coupled elastoplastic damage model of coal-rock, Frattura ed Integrità Strutturale, 53 (2020) 434-445.

Received: 23.04.2020

Accepted: 05.06.2020

Published: 01.07 .2020

Copyright: (C) 2020 This is an open access article under the terms of the CC-BY 4.0, which permits unrestricted use, distribution, and reproduction in any medium, provided the original author and source are credited.

\section{INTRODUCTION}

$\mathrm{T}$ wo types of inelastic behaviors generally exist in most rock materials: plastic deformation, related to sliding mechanisms inside the microstructure of rock matrix; and damage to rock materials, induced by spreading microcracks[1-2]. In the case of semi-brittle rocks, for instance, limestone and porous sandstone, plastic deformation 
and damage are usually coupled. Therefore, it is necessary to develop a coupled elastoplastic damage model to better understand the mechanical behaviors of these semi-brittle geomaterials. Coal is a complex fractured geological medium containing numerous randomly distributed micro holes and cracks [3]. Its mechanical properties are important essential parameters for the mining design, roadway support and some other underground coal engineering [4-5]. Therefore, the constitutive relation and damage model of coal-rock is still a major issue to be solved urgently.

Several elastoplastic models have been proposed for coal-rock in the past, thus providing the standard framework for contemporary models [6-9]. The last two decades of geomechanic research have led to an active discussion of damage models for geomaterials, to better address microcracks. A series of isotropic and anisotropic damage models have been proposed. These approaches can be classified into two groups: (macroscopic) phenomenological and micromechanical models. The phenomenological damage models can be easily implemented in computer codes, which then provide an efficient tool for progressive failure analysis of coal-rock mass structures under complex loading conditions. Additionally, the phenomenological damage models generally take the thermodynamics of irreversible processes into account; they make use of different orders of tensorial internal variables to represent the distribution and nucleation and growth of microcracks [10-13]. However, in these coupled models, the choice of damage variables and thermodynamic potential is somewhat arbitrary, because it is based on mathematical conveniences, rather than the physical interpretation of microcracks. Moreover, most of the previous coupled elastoplastic damage models are isotropic, rather than anisotropic, models. But in fact, the anisotropic features of geomaterials are observable in triaxial and uniaxial compressive tests.

The micromechanical damage mechanics approach leads to an improved understanding of the underlying physical processes. In the micromechanical approach, researchers study the growth, nucleation, and coalescence of microcracks and their influence on the mechanical properties, which is reflected in the constitutive relation in certain ways [9, 14-17]. Among these, the most widely used models are the dilute-concentration method (DCM), the self-consistent method [18-20], the differential method (DM) [21, 22], the generalized self-consistent method (GSCM) [23], and finally, the effective selfconsistent method [24]. However, the micromechanical damage mechanics model is often difficult to implement in engineering applications, because of its proclivity to cause 3D problems.

Therefore, the phenomenological approach is adapted in the new model. This article proposes a novel coupled elastoplastic damage model for coal-rock to discuss the plastic deformation and induced damage found in coal mine. In section 2, reconstituted coal samples were manufactured in size of $50 \mathrm{~mm} \times 100 \mathrm{~mm}$ by compressing machine. Then triaxial compression tests of coal-rock under four confining stresses of $0 \mathrm{MPa}, 5 \mathrm{MPa}, 10 \mathrm{MPa}$ and $15 \mathrm{MPa}$ are conducted. The complete deviatoric stress-strain curves of the coal-rock under the different confining stress conditions are obtained. Moreover, in section 3, a novel coupled elastoplastic damage model for coal-rock is proposed to predict the deformation. The conditions of small deformation and thermodynamic potential are considered, as well as the coupling of damage evolution process with the plastic deformation and the plastic hardening of coal-rock. Based on the theory of damage mechanics, the formulas of damage evolution, plastic yield and plastic potential of coal-rock are deduced theoretically. In section 4, the theoretical results obtained from the coupled elastoplastic damage model for coal-rock agree well with those from the experiment. It is demonstrated that the proposed model is reasonable to predict the deformation of coal-rock.

\section{EXPERIMENT STUDY ON AND RESULT OF THE TRIAXIAL COMPRESSION DEFORMATION OF COAL AND ROCK}

\section{$\mathrm{I}$}

Sample preparation $\mathrm{n}$ this paper, reconstituted coal samples were used to investigate the mechanical property of coal-rock. The pulverized coal was collected from Songzao coal mining area in Chongqing. Then in laboratory, the pulverized coal and water were mixed first and stirred evenly, as shown in Fig. 1 (a). The reconstituted coal samples were made by compressing machine, as shown in Fig. 1(b). The compression of the pulverized coal was stress-controlled with a loading rate of $200 \mathrm{~N} / \mathrm{s}$ until the axial load reached $150 \mathrm{kN}$. The diameter and length of coal sample were $50 \mathrm{~mm}$ and $100 \mathrm{~mm}$, respectively. Four groups (each group contained 5 samples) coal samples were prepared for the triaxial compression test with different confining stresses. The samples were dried in a thermostat at $28^{\circ} \mathrm{C}$ for 30 days. The reconstituted coal sample is shown in Fig. 1(c).

\section{Experimental apparatus}

In this paper, the triaxial compression test of coal-rock were conducted using the Servo-controlled Rock Mechanical Test System MTS815, as shown in Fig. 2(a) and Fig. 2(b). The axial stress, the axial displacement and the circumferential displacement under different confining stresses can be obtained using MTS815. The triaxial compression tests of coal-rock 
have four confining stresses of $0 \mathrm{MPa}, 5 \mathrm{MPa}, 10 \mathrm{MPa}$ and $15 \mathrm{MPa}$. All tests were conducted under displacement-controlled conditions at average loading rate of $0.01 \mathrm{~mm} / \mathrm{min}$ until the coal-rock sample is failure.
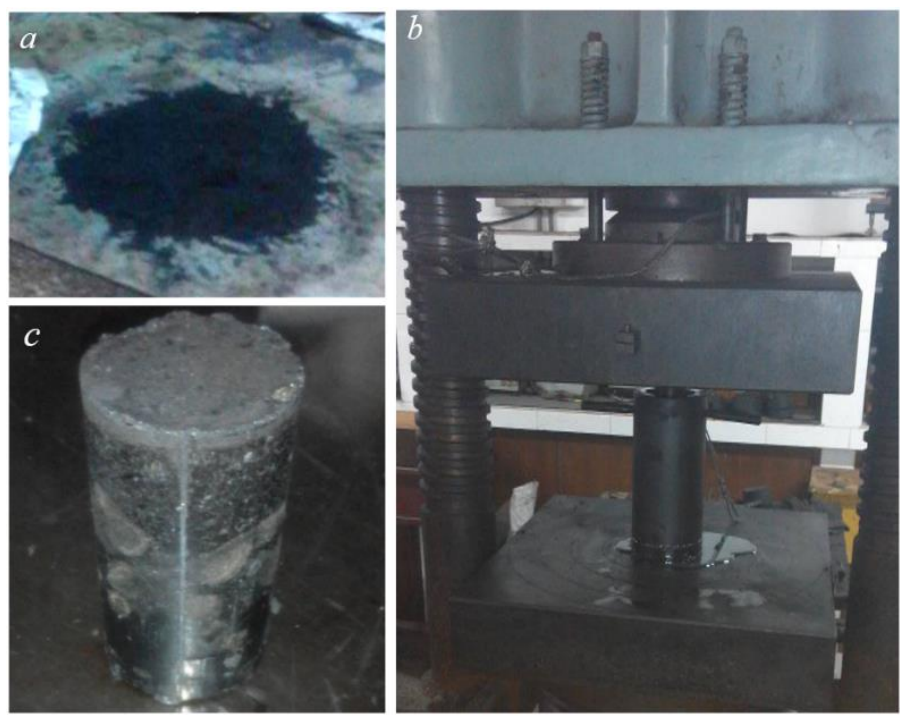

Figure 1: The preparation of coal samples. (a) The pulverized coal collected from Songzao coal mining area in Chongqing; (b) The stresscontrolled compressing machine for manufacture the coal samples; (c) The reconstituted coal sample.
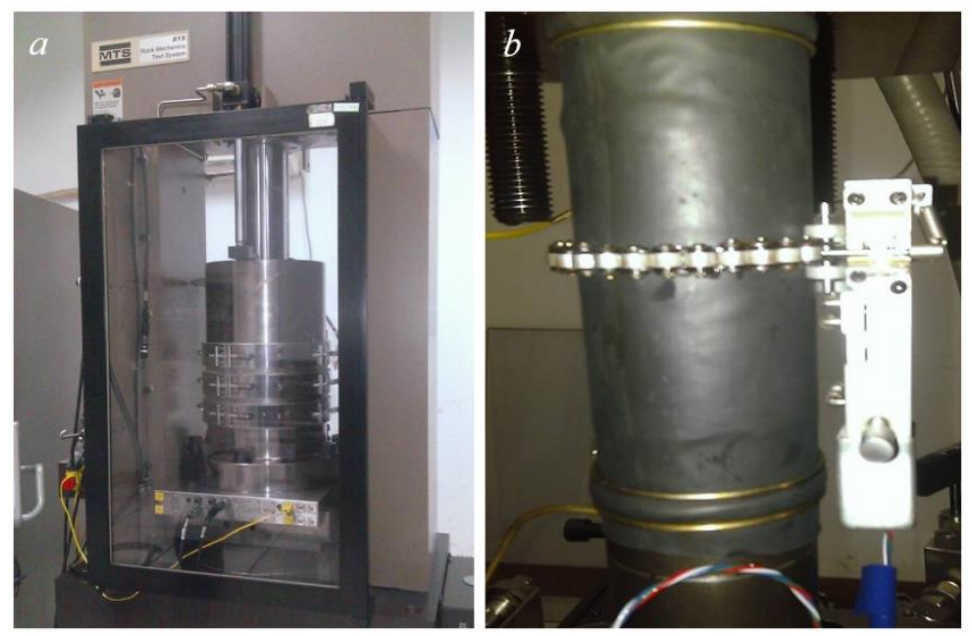

Figure 2: The rock mechanical triaxial test system. (a) The Servo-controlled Rock Mechanical Test System MTS815; (b) The installation of the coal samples.

\section{Experimental results}

According to the experimental data, the complete deviatoric stress-strain curves of the coal-rock under the different confining stress conditions can be obtained, as shown in Figs 3-6. It is found from Figs 3-6 that the overall trends of the complete deviatoric stress-strain curves are similar. The characteristics of the complete deviatoric stress-strain curves can be divided into three stages, which are the linear elastic stage, the elastic damage stage and the plastic damage stage. As shown in Fig. 3, the peak deviatoric stress $\sigma_{1}-\sigma_{3}$ of the coal-rock is $4.576 \mathrm{MPa}$ and the corresponding axial strain $\varepsilon_{1}$ is $0.518 \%$ when the confining stress is $0 \mathrm{MPa}$. As shown in Fig. 4, the peak deviatoric stress $\sigma_{1}-\sigma_{3}$ of the coal-rock is 9.442 $\mathrm{MPa}$ and the corresponding axial strain $\varepsilon_{1}$ is $1.765 \%$ and the corresponding transverse strain $\varepsilon_{3}$ is $-0.956 \%$ when the confining stress is $5 \mathrm{MPa}$. As shown in Fig. 5, the peak deviatoric stress $\sigma_{1}-\sigma_{3}$ of the coal-rock is $12.832 \mathrm{MPa}$ and the corresponding axial strain $\varepsilon_{1}$ is $3.146 \%$ and the corresponding transverse strain $\varepsilon_{3}$ is $-1.771 \%$ when the confining stress is $10 \mathrm{MPa}$. As shown in Fig. 6 , the peak deviatoric stress $\sigma_{1}-\sigma_{3}$ of the coal-rock is $13.521 \mathrm{MPa}$ and the corresponding 
axial strain $\varepsilon_{1}$ is $3.583 \%$ and the corresponding transverse strain $\varepsilon_{3}$ is $-1.872 \%$ when the confining stress is $15 \mathrm{MPa}$. The elastic modulus of coal-rock is $957 \mathrm{MPa}$ and the Poisson's ratio of coal-rock is 0.36 .

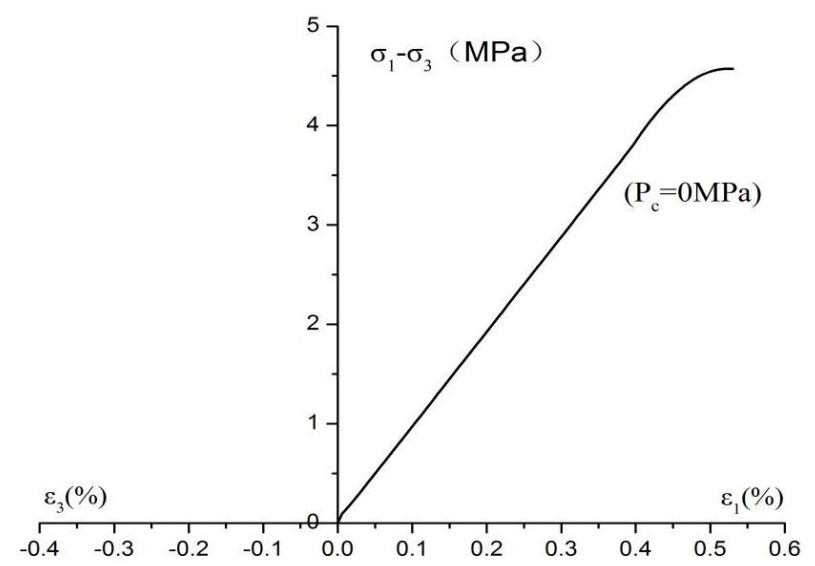

Figure 3: The deviatoric stress versus axial strain under the confining pressure of $0 \mathrm{MPa}$.

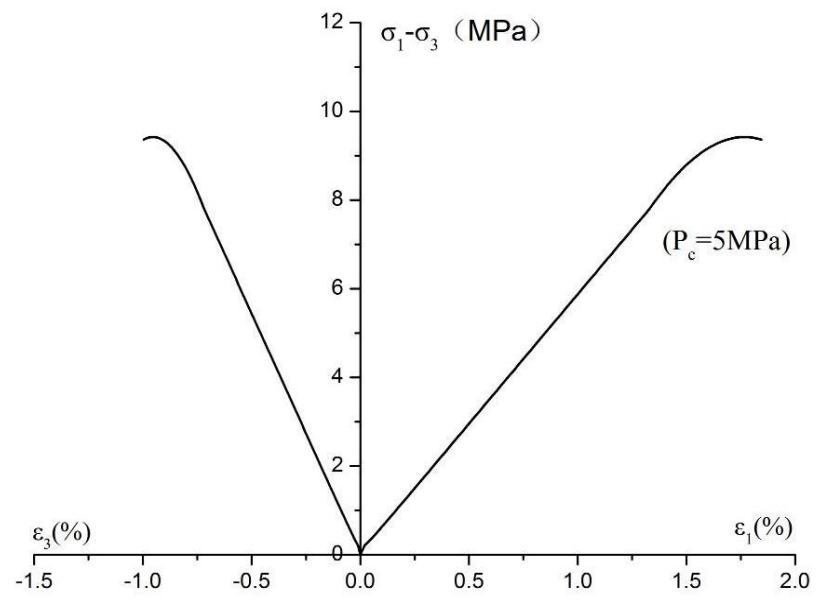

Figure 4: The deviatoric stress $\sigma_{1}-\sigma_{3}$ versus axial strain $\varepsilon_{1}$ and transverse strain $\varepsilon_{3}$ under the confining pressure of $5 \mathrm{MPa}$.

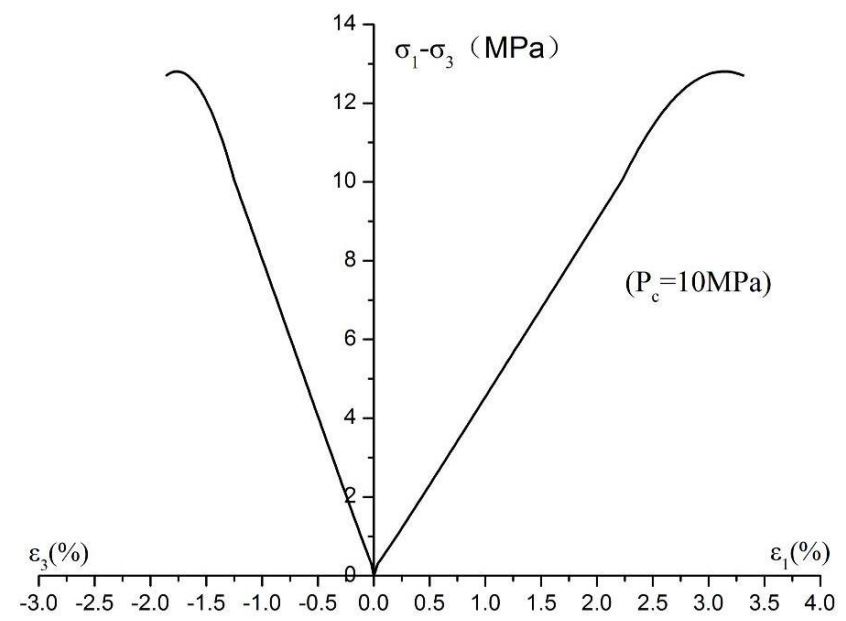

Figure 5: The deviatoric stress $\sigma_{1}-\sigma_{3}$ versus axial strain $\varepsilon_{1}$ and transverse strain $\varepsilon_{3}$ under the confining pressure of $10 \mathrm{MPa}$. 


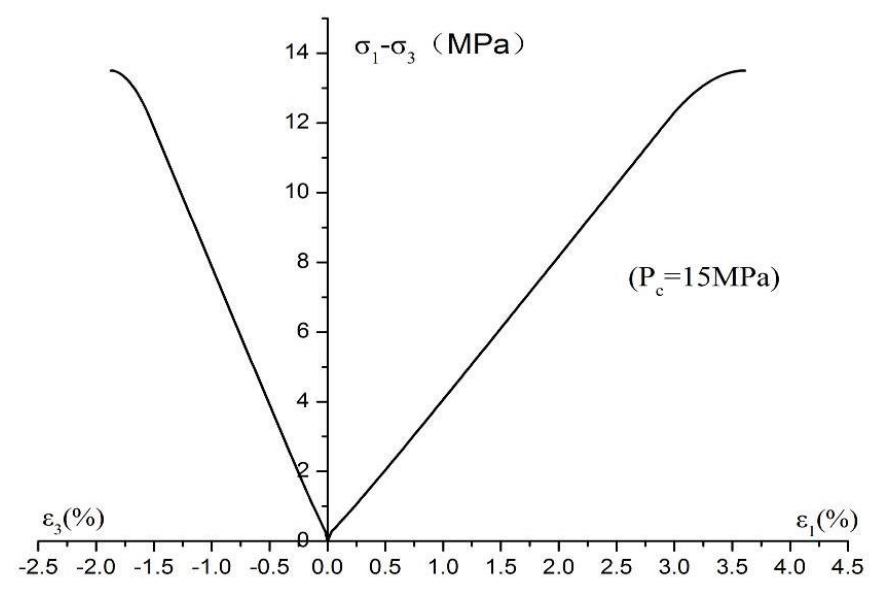

Figure 6: The deviatoric stress $\sigma_{1}-\sigma_{3}$ versus axial strain $\varepsilon_{1}$ and transverse strain $\varepsilon_{3}$ under the confining pressure of $15 \mathrm{MPa}$.

\section{ELASTOPLASTIC DAMAGE COUPLED MODEL OF COAL-ROCK}

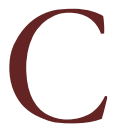

ontinuum damage mechanics is investigated based on macro phenomenological theory, which deals with dissipative systems. In the dissipative systems, the whole damage process is irreversible and always accompanied by internal energy dissipation. In the study of irreversible processes, some basic principles (such as conservation of mass, conservation of momentum moment, conservation of momentum, etc.) must be satisfied. For irreversible processes, there is always energy dissipation within the system. The irreversible phenomenon of energy dissipation within the system is related to internal state variables. The basic state variables can be taken as thermodynamic temperature and strain. In continuum damage mechanics, the internal state variables involve the elastic strain tensor $\varepsilon^{e}$, the plastic strain tensor $\varepsilon^{p}$, the cumulative inverse strain $\gamma^{p}$ and the damage variable $d$ and so on.

\section{Mechanical characteristics of coal-rock}

Firstly, elastic modulus, Poisson's ratio, tensile strength, internal cohesion and internal friction angle of coal-rock are the basic mechanical properties of coal. According to the experimental results above, the mechanical properties of coal-rock are low modulus of elasticity, low strength and high Poisson's ratio. Moreover, it is easy to produce plastic deformation. The axial failure stress and modulus of coal-rock are related to confining stress closely.

Secondly, many micro-cracks, micro-pores and weak structural planes exist in coal-rock, as shown in Fig. 7. The existence of these micro-cracks determines the internal structure of coal-rock, which lead to the heterogeneity and anisotropy of coalrock. Therefore, coal-rock is a typical geotechnical material with internal defects. Because the stress concentration at the cracks or the micro-pores will occur in the process of loading, the coal-rock will be destroyed.
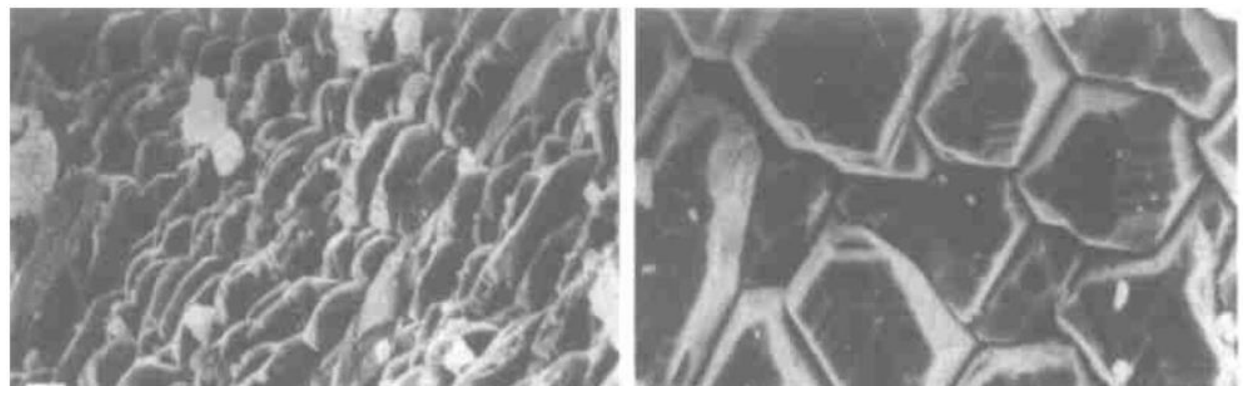

Figure 7: The micro-pores and micro-cracks in coal-rock [25].

The elastoplastic coupled damage model of coal-rock

In this paper, an elastoplastic coupling model is proposed to describe the mechanical properties of coal and rock. Under the isothermal conditions, the state variables are composed of the elastic strain tensor $\varepsilon^{e}$, the plastic strain tensor $\varepsilon^{p}$, the 
damage variable $d$ and the cumulative inverse strain $\gamma^{p}$. The total strain $\varepsilon$ are divided into two parts, namely the elastic strain $\varepsilon^{e}$ and the plastic strain $\varepsilon^{p}$.

$$
\varepsilon=\varepsilon^{e}+\varepsilon^{p} \text { and } d \varepsilon=d \varepsilon^{e}+d \varepsilon^{p}
$$

where $d \varepsilon$ is the incremental total strain, $d \varepsilon^{e}$ is the incremental elastic strain $d \varepsilon^{e}$ is the incremental plastic strain. As stated by Shao et al. [9], the damage process is coupled with plastic deformation and plastic hardening. Therefore, the thermodynamic potential can be expressed as

$$
\Psi=\frac{1}{2}\left(\varepsilon-\varepsilon^{p}\right): C(d):\left(\varepsilon-\varepsilon^{p}\right)+\Psi_{p}\left(\gamma_{p}, d\right)
$$

where $C(d)$ is the fourth-order elastic stiffness tensor of the damaged coal-rock and $\Psi_{p}\left(\gamma_{p}, d\right)$ is the closed plastic potential of the damaged coal-rock related to plastic hardening.

Then, the equation of state can be obtained by deriving the elastic strain $\varepsilon^{\mathrm{e}}$ from the thermodynamic potential as [9]

$$
\sigma=\frac{\partial \Psi}{\partial \varepsilon^{e}}=C(d):\left(\varepsilon-\varepsilon^{p}\right)
$$

According to works by Nemat-Nasser and Hori [26], the fourth-order elastic stiffness tensor can be expressed as

$$
C(d)=3 k(d) J+2 \mu(d) K
$$

where $k(d)$ is the bulk modulus of damaged materials and $\mu(d)$ is shear modulus of damaged materials. The other two symmetric four-order tensors $J$ and $K$ are

$$
J=\frac{1}{3} \delta \otimes \delta \text { and } K=I-J
$$

where $\delta$ is the two-order unit tensor, $I$ is the symmetric four-order unit tensors.

The thermal forces related to the damage variable is expressed as [?]

$$
Y_{d}=-\frac{\partial \Psi}{\partial d}=-\frac{1}{2}\left(\varepsilon-\varepsilon^{p}\right): \frac{\partial C(d)}{\partial d}:\left(\varepsilon-\varepsilon^{p}\right)-\frac{\partial \Psi_{p}\left(\gamma_{p}, d\right)}{\partial d}
$$

According to the non-negativity of the internal energy dissipation, the following expression can be obtained [9]

$$
\sigma: \dot{\varepsilon}^{p}+Y_{d} \dot{d} \geq 0
$$

where $\sigma$ is the stress tensor of coal-rock, $\dot{\varepsilon}^{p}$ is the derivation of $\varepsilon^{p}$ to time $t$ and $\dot{d}$ is the derivation of $d$ to time $t$. Then, the derivative form of the constitutive equation of coal-rock can be obtained as [9]

$$
\begin{aligned}
\dot{\sigma} & =C(d): \dot{\varepsilon}^{e}+\frac{\partial C(d)}{\partial d}: \varepsilon^{e} \dot{d} \\
& =C(d):\left(\dot{\varepsilon}-\dot{\varepsilon}^{p}\right)+\frac{\partial C(d)}{\partial d}:\left(\varepsilon-\varepsilon^{p}\right) \dot{d}
\end{aligned}
$$

where $\dot{\sigma}$ is the derivation of $\sigma$ to time $t$. 


\section{COMPARISON OF ELASTOPLASTIC DAMAGE COUPLED MODEL OF COAL AND ROCK WITH EXPERIMENTAL RESULTS}

\section{Determination of damage evolution characteristics of coal and rock}

7 he elastoplastic coupling model is established in section 3.2. According to Eqn. (4), the elastic stiffness matrix of isotropic damaged materials is expressed by shear modulus and bulk modulus. Moreover, the elastic modulus and Poisson's ratio vary with the damage variable $d$. Based on Eqn. (4), the effect of damage on elastic mechanical properties can be determined accurately. For the moderate damage condition, the degradation of elastic mechanical properties [26-28] can be expressed as

$$
k(d)=k_{0}(1-\alpha d), \quad \mu(d)=\mu_{0}(1-\beta d)
$$

where $k_{0}$ and $\mu_{0}$ are respectively the bulk modulus and shear modulus of undamaged materials, $\alpha$ and $\beta$ are the two parameters of coal-rock to present the effect of damage on the elastic mechanical properties of coal-rock.

According to the damage criterion, the thermal forces related to the damage variable $Y_{d}$ can be linearized as

$$
Y_{d}=Y_{d}^{0}+m d
$$

where $Y_{d}^{0}$ is the initial energy release threshold, $m$ is a parameter to control the damage evolution rate.

\section{Determination of expression of plastic properties of coal and rock}

The yield equation of coal and rock includes some main characteristics, such as pressure sensitivity, unconnected plastic flow, asymmetric response under pressure and tension loading, plastic hardening and so on. The three-dimensional nonlinear strength criterion proposed by Zhou et al. [29] is introduced to determine yield surface of coal-rock, which is expressed as follows:

$$
F^{p}(\sigma)=\sigma_{1}-\sigma_{3}-\sqrt{\left(n \sigma_{2}+m \sigma_{3}\right) \sigma_{c}+\sigma_{c}^{2}}
$$

where $n$ and $m$ are the strength parameters, $\sigma_{c}$ denotes uniaxial compressive strength of rocks, $\sigma_{1}, \sigma_{2}, \sigma_{3}$ are the major, intermediate and minor principal stresses, respectively.

When the damage variable is considered, the nonlinear strength criterion Eqn. (11) is rewritten in another form

$$
\begin{aligned}
F^{p}\left(\sigma, \gamma_{p}, d\right) & =2 \sqrt{3 J_{2}} \cos \phi_{\sigma} \\
& -\sqrt{\sigma_{c}\left\{3 \sigma_{c}\left(1-\frac{t r d}{3}\right)+I_{1}(m+n)-\sqrt{J_{2}}\left[3 m \cos \phi_{\sigma}+\sqrt{3}(m-2 n) \sin \phi_{\sigma}\right]\right\}}=0
\end{aligned}
$$

where the stress angle is equal to $\phi_{\sigma}=\arctan \left[\frac{2 \sigma_{3}-\left(\sigma_{1}+\sigma_{2}\right)}{\sqrt{3}\left(\sigma_{1}+\sigma_{2}\right)}\right],-30^{\circ} \leq \phi_{\sigma} \leq 30^{\circ}, I_{1}$ is the first invariant of stress, $J_{2}$ is the second invariant of deviator stress, $\sigma_{c}$ is an uniaxial compressive strength of an intact rock material, $m$ and $n$ are strength parameters of rocks.

The cumulative inverse strain can be determined as

$$
\dot{\gamma}_{p}=\sqrt{\frac{2}{3} \dot{e}^{p}: \dot{e}^{p}}
$$

where $e^{p}=\varepsilon^{p}-\frac{1}{3} \operatorname{tr} \varepsilon^{p} \delta$ 
Determination of thermodynamic potential of coal and rock

In this paper, it is assumed that the plastic flow is in the state of strain hardening. Under the assumption of moderate damage, the closed plastic potential of the damaged coal-rock can be simplified as

$$
\Psi_{p}\left(\gamma_{p}, d\right)=(1-\chi d) \Psi_{p}^{0}\left(\gamma_{p}\right)
$$

where $\Psi_{p}^{0}\left(\gamma_{p}\right)$ is the plastic hardening rate without damage. We introduce parameters $\chi \in[0,1]$ in the coupling of damage evolution and plastic flow. If $\chi=0$, there is no coupling between damage evolution and plastic flow. If $\chi=1$, the model is a total damage model. Based on the experimental data of coal-rock, the expression of plastic hardening rate without damage are proposed as

$$
\psi_{p}^{0}=\alpha_{p}^{m} \gamma_{p}^{2}-\left(\alpha_{p}^{m}-\alpha_{p}^{0}\right) \gamma_{p}-B\left(\alpha_{p}^{m}-\alpha_{p}^{0}\right)
$$

The plastic hardening rate of damaged materials can be written as

$$
\alpha_{p}=\frac{\partial \psi}{\partial \gamma_{p}}=(1-\chi d)\left[2 \alpha_{p}^{0} \gamma_{p}+\left(\alpha_{p}^{m}-\alpha_{p}^{0}\right)\left(2 \gamma_{p}-1\right)\right]
$$

where $\alpha_{p}^{0}$ is the initial plastic yield threshold, $\alpha_{p}^{m}$ is the final value of the hardening equation and $B$ is the model parameter controlling the plastic hardening rate.

In geotechnical materials, there is a transition from plastic compression to plastic expansion based on loading path [30, 31]. the expression of plastic potential can be determined as

$$
g=q h(\theta)+(1+\chi d) \eta(p-C) \ln \left(\frac{p-C}{I_{0}}\right)=0
$$

where $I_{0}$ define the intersection point of plastic potential surface and $p$ axis. The boundary of compression and expansion regions is defined by conditions of $\partial g(p, q) / \partial p=0$. It is assumed that $p$ and $q$ are both linear. Then, the expression of plastic potential can be simplified as

$$
\bar{f}_{c d}=q h(\theta)-(1-\chi d) \eta(p-C)=0
$$

where $\eta$ is the boundary diagonals between the compression and expansion regions.

The parameters of the coupled elastoplastic damage model of coal-rock

Twelve parameters involved in the coupled elastoplastic damage model of coal-rock, including two elastic constants of undamaged materials $k_{0}$ and $\mu_{0}$, two parameters of coal-rock to present the effect of damage on the elastic mechanical properties of coal-rock $\alpha$ and $\beta$, five parameters related to plastic characteristics $\alpha_{p}^{0}, \alpha_{p}^{m}, C, B, \eta$, two parameters related to damage characteristics $Y_{d}^{0}$ and $m$, and one parameter related to plastic-damage coupling $\chi$. All these parameters can be obtained from a series of triaxial compression tests under different confining pressures. The values of parameters are listed in Tab. 1.

Substituting the parameters in Tab. 1 into Eqns. (8)-(22), the theoretical results of deviatoric stress $\sigma_{1}-\sigma_{3}$ versus axial strain $\varepsilon_{1}$ and transverse strain $\varepsilon_{3}$ can be obtained. The curves of deviatoric stress $\sigma_{1}-\sigma_{3}$ versus axial strain $\varepsilon_{1}$ and transverse strain $\varepsilon_{3}$ under the different confining stresses obtained from the theoretical and experimental results are depicted in Figs 8-11. In this figures, the black solid lines represent the experimental result, and the dotted lines represent the theoretical results. It is found from Figs 8-11 that the theoretical results agree well with experimental data. The 
experiment results prove that the model established in this paper can be well applied to evaluate the constitutive relation of coal-rock.

\begin{tabular}{cc}
\hline Parameters & Values \\
$k_{0} / \mathrm{MPa}$ & 1139.28 \\
$\mu_{0} / \mathrm{MPa}$ & 351.84 \\
$\alpha$ & 0.25 \\
$\beta$ & 0.8325 \\
$\alpha_{p}^{0}$ & 0.00479 \\
$\alpha_{p}^{m}$ & 0.0032 \\
$C / \mathrm{MPa}$ & 1.49 \\
$B$ & $2.5 \times 10^{-4}$ \\
$\eta$ & 3.75 \\
$Y_{d}^{0}$ & 0.683 \\
$m$ & 0.85 \\
$\chi$ & 1.0 \\
\hline
\end{tabular}

Table 1: The values of parameter involved in the proposed model

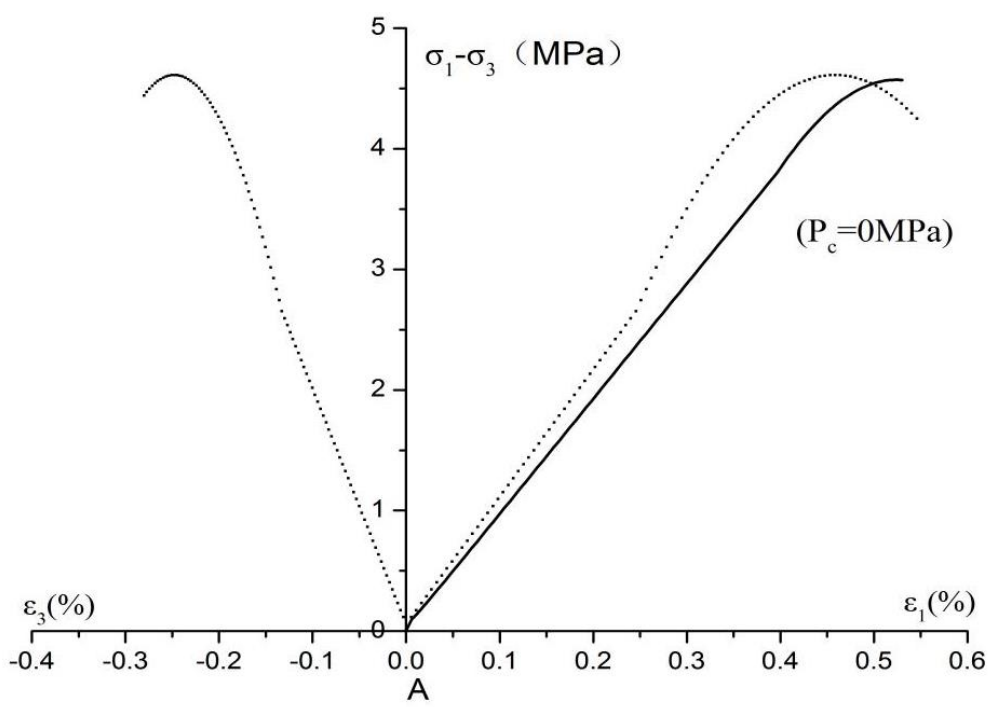

Figure 8: The theoretical and experimental results of deviatoric stress $\sigma_{1}-\sigma_{3}$ versus axial strain $\varepsilon_{1}$ curve when the confining pressure is $0 \mathrm{MPa}$. 


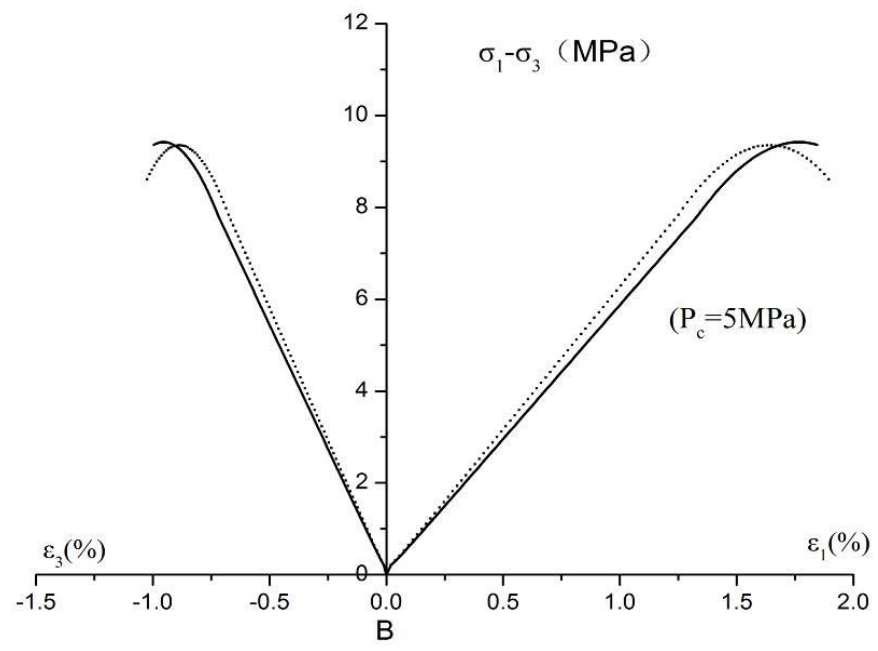

Figure 9: The theoretical and experimental results of deviatoric stress $\sigma_{1}-\sigma_{3}$ versus axial strain $\varepsilon_{1}$ and transverse strain $\varepsilon_{3}$ curve when the confining pressure is $5 \mathrm{MPa}$.

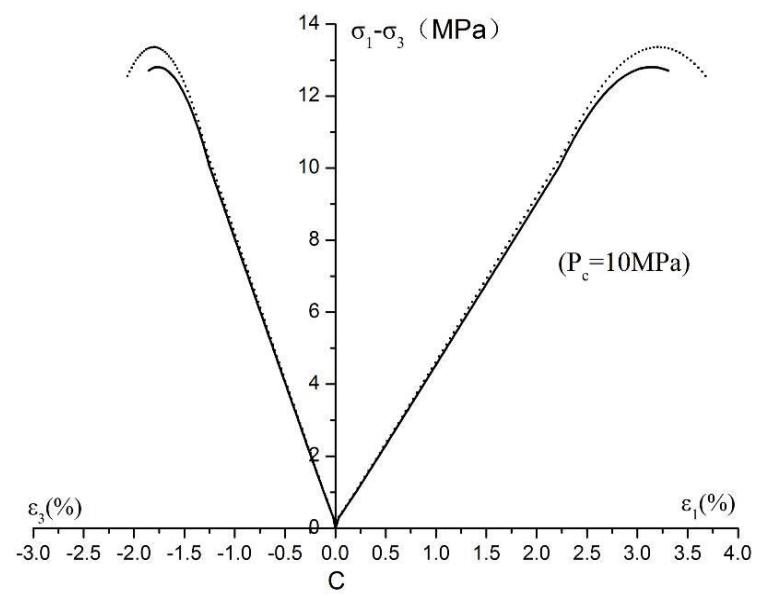

Figure 10: The theoretical and experimental results of deviatoric stress $\sigma_{1}-\sigma_{3}$ versus axial strain $\varepsilon_{1}$ and transverse strain $\varepsilon_{3}$ curve when the confining pressure is $10 \mathrm{MPa}$.

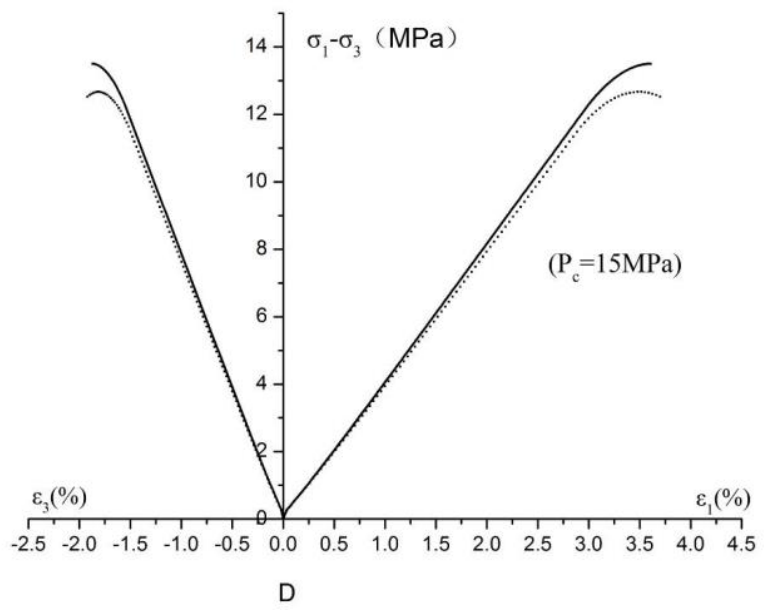

Figure 11: The theoretical and experimental results of deviatoric stress $\sigma_{1}-\sigma_{3}$ versus axial strain $\varepsilon_{1}$ and transverse strain $\varepsilon_{3}$ when the confining pressure is $15 \mathrm{MPa}$. 


\section{CONCLUSION}

novel coupled elastoplastic damage model for coal-rock is proposed to predict the deformation and potential disaster in coal mining. The conditions of small deformation and thermodynamic potential are considered, as well 1 as the coupling of damage evolution process with the plastic deformation and the plastic hardening of coal-rock. Based on the theory of damage mechanics, the formulas of damage evolution, plastic yield and plastic potential of coal-rock are deduced theoretically. In addition, triaxial compression tests of coal-rock under four confining stresses of $0 \mathrm{MPa}, 5 \mathrm{MPa}$, $10 \mathrm{MPa}$ and $15 \mathrm{MPa}$ are conducted to reveal the law of deviatoric stress and strain. Based on the experimental data, the control parameters of the coupled elastoplastic damage model of coal-rock are determined. The theoretical results obtained from the coupled elastoplastic damage model for coal-rock agree well with those from the experiment. The proposed model is reasonable to predict the deformation of coal-rock.

\section{ACKNOWLEDGMENTS}

he work is supported by the National Natural Science Foundation of China (Nos. 41807251, 51809198 and 51839009), and the Fundamental Research Funds for the Central Universities (Grant No. 2042019kf0037).

\section{REFERENCES}

[1] Zhou, X.P., Zhang, J.Z. and Wong, L.N.Y. (2018). Experimental Study on the Growth, Coalescence and Wrapping Behaviors of 3D Cross-Embedded Flaws Under Uniaxial Compression, Rock Mech. Rock Eng., 51(5), pp. 1379-1400. DOI: $10.1007 / \mathrm{s} 00603-018-1406-4$.

[2] Zhou, X.P., Zhang, J.Z., Qian, Q.H and Niu, Y. (2019). Experimental investigation of progressive cracking processes in granite under uniaxial loading using digital imaging and AE techniques, J. Struct. Geol., 126, pp. 129-145.

DOI: 10.1016/j.jsg.2019.06.003.

[3] Liu, X.S., Tan, Y.L., Ning, J.G., Lu, Y.W. and Gu, Q.H. (2018). Mechanical properties and damage constitutive model of coal in coal-rock combined body, Int. J. Rock Mech. Min. Sci., 110, pp. 140-150. DOI: 10.1016/j.ijrmms.2018.07.020.

[4] Poulsen, B.A., Shen, B., Williams, D.J., Huddlestone-Holmes, C., Erarslan, N. and Qin, J. (2014). Strength reduction on saturation of coal and coal measures rocks with implications for coal pillar strength, Int. J. Rock Mech. Min. Sci., 71, pp. 41-52. DOI: 10.1016/j.ijrmms.2014.06.012.

[5] Bertuzzi, R., Douglas, K. and Mostyn, G. (2016). An approach to model the strength of coal pillars, Int. J. Rock Mech. Min. Sci. 89, pp. 165-175. DOI: 10.1016/j.ijrmms.2016.09.003.

[6] Yang, X.B. Xia, Y.J. and Wang, X.J. (2012). Investigation into the nonlinear damage model of coal containing gas, Safety Sci., 50, pp. 927-930. DOI: 10.1016/j.ssci.2011.08.001.

[7] Li, Y.W., Long, M., Zuo, L.H., Li, W. and Zhao, W.C. (2019). Brittleness evaluation of coal based on statistical damage and energy evolution theory, J. Petrol. Sci. Eng., 172, pp. 753-763. DOI: 10.1016/j.petrol.2018.08.069.

[8] Wu, C., Dou, L.M., Ju, Y., Cao, W.Z., Yuan, S.S. and Si, G.Y. (2018). A plastic strain-based damage model for heterogeneous coal using cohesion and dilation angle, Int. J. Rock Mech. Min. Sci., 110, pp. 151-160.

DOI: 10.1016/j.ijrmms.2018.08.001.

[9] Shao, J.F., Jia, Y., Kondo, D. and Chiarelli, A.S. (2006). A coupled elastoplastic damage model for semi-brittle materials and extension to unsaturated conditions, Mech. Mater., 38, pp. 218-232. DOI: 10.1016/j.mechmat.2005.07.002.

[10] Zhou, X.P. (2004). Analysis of the localization of deformation and the complete stress-strain relation for mesoscopic heterogeneous brittle rock under dynamic uniaxial tensile loading, Int. J. Solids Struct., 41(5-6), pp. 1725-1738.

DOI: 10.1016/j.ijsolstr.2003.07.007.

[11] Zhou, X.P., Ha, Q.L., Zhang, Y.X. and Zhu, K.S. (2004). Analysis of deformation localization and the complete stressstrain relation for brittle rock subjected to dynamic compressive loads, Int. J. Rock Mech. Min. Sci., 41(2), pp. 311-319. DOI: $10.1016 /$ S1365-1609(03)00094-7.

[12] Shao, J.F., Lu, Y.F. and Lydzba, D. (2004). Damage modeling of saturated rocks in drained and undrained conditions, J. Eng. Mech., 130(6), pp. 733-740. DOI: 10.1061/(asce)0733-9399(2004)130:6(733). 
[13] Zhou, X.P. Cheng, H. and Feng, Y.F. (2014). An Experimental Study of Crack Coalescence Behaviour in Rock-Like Materials Containing Multiple Flaws Under Uniaxial Compression, Rock Mech. Rock Eng., 47 (6), pp. 1961-1986. DOI: $10.1007 / \mathrm{s} 00603-013-0511-7$.

[14] Chow, C.L. and June, W. (1987). An anisotropic theory of elasticity for continuum damage mechanics, Int. J. Fracture, 33, pp. 3-16. DOI: $10.1007 /$ bf00034895.

[15] Zhou, X.P. and Yang, H.Q. (2007). Micromechanical modeling of dynamic compressive responses of mesoscopic heterogenous brittle rock, Theo. Appl. Fract. Mech., 48(1), pp. 1-20. DOI: 10.1016/j.tafmec.2007.04.008.

[16] Zhou, X.P. (2005). Triaxial compressive behavior of rock with mesoscopic heterogenous behavior: Strain energy density factor approach, Theo. Appl. Fract. Mech., 45(1), pp. 46-63. DOI: 10.1016/j.tafmec.2005.11.002.

[17] Zhou, X.P. (2005). Localization of deformation and stress-strain relation for mesoscopic heterogeneous brittle rock materials under unloading, Theo. Appl. Fract. Mech., 44(1), pp. 27-43. DOI: 10.1016/j.tafmec.2005.05.003.

[18] Zhang, J.X. Wong, T.F. and Davis, D.M. (1990). Micromechanics of pressured-induced grain crushing in porous rocks, J. Geophy. Res., 95, pp. 341-351. DOI: 10.1029/JB095iB01p00341.

[19] Budiansky, B. and O’Connell, R.J. (1976). Elastic moduli of a cracked solid, Int. J. Solids Struct., 12, pp. 81-97. DOI: $10.1016 / 0020-7683(76) 90044-5$.

[20] Zhou, X.P. Zhang, Y.X., Ha, Q.L. and Zhu, K.S. (2008). Micromechanical modelling of the complete stress-strain relationship for crack weakened rock subjected to compressive loading. Rock Mech. Rock Eng., 41(5), pp. 747-769. DOI: $10.1007 / \mathrm{s} 00603-007-0130-2$.

[21] Horii, H. and Nemat-Nasser, S. (1983). Overall moduli of solids with microcracks: load-induced anisotropy, J. Mech. Phys. Solids, 31, pp. 155-171. DOI: 10.1016/0022-5096(83)90048-0.

[22] Zhou, X.P. and Wang, J.H. (2005). Study on the coalescence mechanism of splitting failure of crack-weakened rock subjected to compressive loads, Mech. Res. Commun., 32(2), pp. 161-171. DOI: 10.1016/j.mechrescom.2004.06.003.

[23] Hashin, Z. (1988). The differential scheme and its application to cracked materials, J. Mech. Phys. Solids, 36, pp. 719734. DOI: 10.1016/0022-5096(88)90005-1.

[24] Aboudi, J. and Benveniste, Y. (1987). The effective moduli of cracked bodies in plane deformations, Eng. Fract. Mech., 26(2), pp. 171-184. DOI: 10.1016/0013-7944(87)90195-0.

[25] Zhang, S.X. and Xiao, H.Y. (2000). Study of the pore and micro fracture of the coal reservoirs in the SEM. J. Chin. Electron. Microsc. Soc., 19(4), pp. 531-532. DOI: 10.3969/j.issn.1000-6281.2000.04.070.

[26] Nemat-Nasser, S. and Hori, M. (1993). Micromechanics: Overall properties of heterogeneous materials, North-Holland, Amsterdam. DOI: 10.1115/1.2788912.

[27] Krajcinovic, D. (1996). Damage Mechanics, North-Holland, Amsterdam, The Netherlands. DOI: 10.1016/s01675931(06)x8062-2.

[28] Pensee, V., Kondo, D. and Dormieux, L. (2002). Micromechanical analysis of anisotropic damage in brittle materials, J. Eng. Mech., 128(8), pp. 889-897. DOI: 10.1061/(ASCE)0733-9399(2002)128:8(889).

[29] Zhou, X.P. Shou, Y.D., Qian, Q.H. and Yu, M.H. (2014). Three-dimensional nonlinear strength criterion for rock-like materials based on the micromechanical method, Int. J. Rock Mech. Min. Sci., 72, pp. 54-60. DOI: $10.1016 /$ j.ijrmms.2014.08.013.

[30] Chiarelli, A.S. (2000). Experimental investigation and constitutive modelling of coupled elastoplastic damage in hard argillites, Doctoral thesis, University of Lille.

[31] Pietruszczak, S., Jiang, J. and Mirza, F.A. (1988). An elastoplastic constitutive model for concrete, Int. J. Solids Struct., 24(7), pp. 705-722. DOI: 10.1016/0020-7683(88)90018-2. 